\title{
Smac mimetic and demethylating agents synergistically trigger cell death in acute myeloid leukemia cells and overcome apoptosis resistance by inducing necroptosis
}

\author{
L Steinhart ${ }^{1,2}, \mathrm{~K}$ Belz ${ }^{1,2}$ and S Fulda ${ }^{\star, 1}$
}

Evasion of apoptosis, for example, by inhibitor of apoptosis (IAP) proteins, contributes to treatment resistance and poor outcome in acute myeloid leukemia (AML). Here we identify a novel synergistic interaction between the small-molecule second mitochondria-derived activator of caspases (Smac) mimetic BV6, which antagonizes X-linked IAP, cellular IAP (cIAP)1 and cIAP2, and the demethylating agents 5 -azacytidine or 5-aza-2'-deoxycytidine (DAC) to induce cell death in AML cells, including apoptosis-resistant cells. Calculation of combination index (Cl) confirms that this drug combination is highly synergistic (Cl 0.02-0.4). In contrast, BV6 and DAC at equimolar concentrations do not cause synergistic toxicity against normal peripheral blood lymphocytes, pointing to some tumor cell selectivity. Molecular studies reveal that BV6 and DAC cooperate to trigger the activation of caspases, mitochondrial perturbations and DNA fragmentation, consistent with apoptotic cell death. However, the broad-range caspase inhibitor $\mathrm{N}$-benzyloxycarbonyl-Val-Ala-Asp-fluoromethylketone (zVAD.fmk) fails to protect against BV6/DAC-induced cell death and even significantly increases the percentage of Annexin-V/propidium iodide double-positive cells. Importantly, BV6/DAC-induced cell death in the presence of ZVAD.fmk is significantly reduced by pharmacological inhibition of key components of necroptosis signaling, that is, receptor-interacting protein (RIP) 1 using necrostatin-1 or mixed lineage kinase domain-like protein (MLKL) using necrosulfonamide. This indicates a switch from BV6/DAC-induced cell death from apoptosis to necroptosis upon caspase inhibition. Thus, BV6 cooperates with demethylating agents to induce cell death in AML cells and circumvents apoptosis resistance via a switch to necroptosis as an alternative mode of cell death. The identification of a novel synergism of BV6 and demethylating agents has important implications for the development of new treatment strategies for AML. Cell Death and Disease (2013) 4, e802; doi:10.1038/cddis.2013.320; published online 12 September 2013

Subject Category: Cancer

AML is the most common malignant myeloid disease in adults. ${ }^{1}$ As a fast turnover of cells represents a hallmark of the lympho-hematopoeitic system, too little programmed cell death can favor leukemogenesis. ${ }^{2,3}$ In addition, impaired cell death pathways can cause treatment resistance, as various cytotoxic principles that are currently used in the clinic for the treatment of $A M L$ exert their antileukemic activity by engaging cell death pathways in AML cells. ${ }^{4}$ Because of the limitations of the established cytotoxic chemotherapy for AML, alternative approaches are required to improve treatment outcome, including strategies to target cell death pathways.

Evasion of programmed cell death belongs to the hallmarks of human cancers, including leukemia. ${ }^{5}$ There are several forms of programmed cell death, including apoptosis and necroptosis. ${ }^{6}$ Apoptosis signals via two key pathways, that is, the death receptor (extrinsic) and the mitochondrial (intrinsic) pathway. ${ }^{4}$ Stimulation of death receptors, for example, CD95 or tumor necrosis factor (TNF) receptor 1 (TNFR1), by their respective ligands, for example, CD95 ligand or TNF $\alpha$, leads to caspase-8 activation, which in turn can cleave downstream effector caspases, such as caspase-3. ${ }^{7}$ The activation of the mitochondrial pathway results in caspase- 3 activation via the release of mitochondrial intermembrane space proteins into the cytosol, including cytochrome c and Smac. ${ }^{8}$ Necroptosis is another regulated mode of cell death that typically occurs under circumstances in which caspase

\footnotetext{
${ }^{1}$ Institute for Experimental Cancer Research in Pediatrics, Goethe-University, Frankfurt, Germany

*Corresponding author: S Fulda, Institute for Experimental Cancer Research in Pediatrics, Goethe-University Frankfurt, Komturstrasse 3a, Frankfurt 60528, Germany. Tel: +49 69 67866557; Fax: +49 69 6786659157; E-mail: simone.fulda@kgu.de

${ }^{2}$ These authors share first authorship.

Keywords: apoptosis; necroptosis; Smac; leukemia; RIP1

Abbreviations: 5AC, 5-azacytidine; ALL, acute lymphoblastic leukemia; AML, acute myeloid leukemia; Bcl-2, B-cell lymphoma 2; CBF, core-binding factor; $\mathrm{Cl}$, combination index; clAP, cellular IAP; DAC, 5-aza-2'-deoxycytidine; FADD, FAS-associated death domain protein; FCS, fetal calf serum; FLT3, Fms-like tyrosine kinase 3; FSC/SSC, forward/side scatter; IAP, inhibitor of apoptosis protein; MFL, MegaFas ligand; MLKL, mixed lineage kinase domain-like protein; MMP, mitochondrial membrane potential; NAC, N-acetyl-cysteine; Nec-1, necrostatin-1; NF- $\kappa$ B, nuclear factor- $\kappa \mathrm{B}$; NSA, necrosulfonamide; PI, propidium iodide; PBL, peripheral blood lymphocyte; RING, really interesting new gene; RIP1, receptor-interacting protein 1; ROS, reactive oxygen species; Smac, second mitochondria-derived activator of caspases; TNF, tumor necrosis factor; TNFR1, TNF receptor 1; TRAIL, TNF-related apoptosis-inducing ligand; XIAP, X-linked IAP; zVAD.fmk, N-benzyloxycarbonyl-ValAla-Asp-fluoromethylketone

Received 04.3.13; revised 25.7.13; accepted 29.7.13; Edited by A Stephanou
} 
activation is absent or blocked. ${ }^{9}$ The serine/threonine kinase RIP1 has been identified as a key regulator of necroptosis, ${ }^{9}$ as well as MLKL was recently discovered as a new component of the necroptotic machinery. ${ }^{10}$ Apoptotic and necroptotic pathways are closely intertwined, as caspase-8 can cleave RIP1, thereby shutting down necroptosis. ${ }^{11}$

IAP proteins represent a family of eight human proteins. ${ }^{12}$ Although X-linked IAP (XIAP) exerts its antiapoptotic function by binding to and inhibiting effector caspase- 9 and $-3 /-7$ via its baculovirus IAP repeat domains, ${ }^{13}$ clAP1 and clAP2 primarily act as E3 ubiquitin ligases via their really interesting new gene (RING) domain that mediates hetero- or autoubiquitination. ${ }^{14}$ For example, clAP1 and clAP2 mediate K63-linked ubiquitination of RIP1 that favors the interaction of RIP1 with components of the canonical nuclear factor $-\kappa B(N F-\kappa B)$ signaling cascade and NF- $\kappa$ B activation. ${ }^{14,15}$ Once deubiquitinated, RIP1 can promote programmed cell death either via the formation of a RIP1/FAS-associated death domain protein (FADD)/caspase-8 complex and induction of apoptosis or, alternatively, via formation of a RIP1/FADD/RIP3 complex and induction of necroptosis. ${ }^{9}$

Elevated expression of IAP proteins has been detected in various human malignancies and has been linked to refractory disease and poor outcome. ${ }^{12}$ In AML, the overexpression of XIAP has previously been associated with poor outcome. ${ }^{16,17}$ Moreover, a three-gene expression signature, including high c-IAP2 mRNA expression, correlated with poor overall survival in $A M L .{ }^{18}$ In core-binding factor (CBF) AML, deregulated apoptotic signaling and IAP protein levels have been shown to differentiate two clinically distinct CBF subgroups with significant differences in clinical outcome. ${ }^{19,20}$

To antagonize IAP proteins, a series of small-molecule IAP inhibitors, including Smac mimetic, have been developed in recent years. ${ }^{12}$ Smac mimetic has been shown to interfere with the XIAP-imposed inhibition of caspases ${ }^{12}$ and to trigger autoubiquitination and proteasomal degradation of IAP proteins with a RING domain, such as CIAP1/2 and XIAP. ${ }^{21-23}$ Clinical trials with Smac mimetics as single agents and in combination with chemotherapy are currently ongoing in advanced solid tumors and lymphoma. ${ }^{12}$ As far as AML is concerned, a phase $\mathrm{I} / \mathrm{II}$ clinical trial has recently been launched, testing the Smac mimetic TL32711 as single agent in relapsed elderly patients (www.clinicaltrials.gov).

In preclinical studies, Smac mimetic as single agent turned out to exhibit little antitumor activity against the majority of tumors, whereas it synergized together with other cytotoxic stimuli to suppress tumor growth. ${ }^{12}$ This highlights the relevance to design Smac mimetic-based rational combinations to exploit Smac mimetic for anticancer therapy. We previously reported that small-molecule IAP inhibitors enhance TNF-related apoptosis-inducing ligand (TRAIL)-, Fas ligand- or chemotherapy-induced apoptosis in childhood acute lymphoblastic leukemia (ALL). ${ }^{24-26}$ However, little is yet known about the potential of Smac mimetic in combination therapies in AML. Major options for novel drugs under investigation in AML include epigenetic drugs, such as demethylating agents, which are currently tested in clinical trials. ${ }^{27}$ Searching for novel treatment strategies for AML, we investigated in the present study the effect of the small- molecule Smac mimetic BV6, which neutralizes XIAP, cIAP1 and $\mathrm{clAP} 2,{ }^{21}$ in combination with demethylating agents.

\section{Results}

BV6 and demethylating agents synergize to induce cell death in AML cells. Demethylating agents are currently under investigation in clinical trials for the treatment of AML. ${ }^{27}$ We previously reported that demethylating agents can prime cancer cells to apoptosis. ${ }^{28,29}$ Searching for novel combination regimens with Smac mimetic, we investigated the effect of the small-molecule Smac mimetic BV6, which neutralizes XIAP, cIAP1 and cIAP2, ${ }^{21}$ in the presence and absence of the DNA methyltransferase inhibitors 5-azacytidine (azacytidine, 5AC) or 5-aza-2'-deoxycytidine (decitabine, DAC) against several AML cell lines with different molecular characteristics (Supplementary Table 1). Importantly, BV6 and 5AC acted in concert to trigger cell death in several AML cell lines compared with either agent alone (Figure 1a). Similarly, BV6 cooperated with DAC to induce cell death in AML cells (Figure 1b). Calculation of $\mathrm{Cl}$ showed that BV6 interacted with either $5 A C$ or DAC in a highly synergistic manner, underscoring the potency of this combination treatment (Supplementary Table 2). Kinetic analysis of cell death revealed that BV6 cooperated with $5 A C$ or DAC in a time-dependent manner (Figures $2 a$ and $b$ ). To confirm this synergistic interaction of BV6 and demethylating drugs by another cell death assay, we also used propidium iodide $(\mathrm{PI})$ staining to analyze plasma membrane permeability. Similarly, BV6 and DAC acted in concert to trigger increased plasma membrane permeability compared with cells treated with either BV6 or DAC alone (Figure 2c).

As we were concerned about the potential toxicity of the combination treatment, we also tested BV6 in combination with DAC against normal cells. To this end, we isolated peripheral blood lymphocytes (PBLs) from different healthy donors. Of note, the combination of BV6 and DAC did not show increased toxicity against PBLs at equimolar concentrations that synergized to induce cell death in AML cells (Figure 2d).

Together, this set of experiments demonstrates that the Smac mimetic BV6 and the demethylating agents $5 A C$ and DAC synergistically trigger cell death in AML cells, but not in normal PBLs, thus pointing to some tumor cell selectivity.

BV6/DAC-induced cell death partly depends on TNF $\alpha$ autocrine/paracrine loop. To gain insights into the molecular mechanisms underlying the synergistic interaction of BV6 and DAC in AML cells, we focused our further mechanistic studies on two AML cell lines (MV4-11 and NB4) and on DAC, as DAC proved to be superior to $5 A C$ when it comes to cooperating with BV6. As Smac mimetic has been described to cause autoubiquitination and proteasomal degradation of IAP proteins, ${ }^{14,21,22,30}$ we examined the effect of BV6 alone and in combination with DAC on IAP protein levels. BV6 caused downregulation of clAP1, clAP2 and XIAP levels, except for clAP2 in MV4-11 cells, which express little amount of clAP2 protein (Figure 3a). Interestingly, treatment with DAC decreased protein levels of clAP1 and XIAP, too (Figure 3a). 

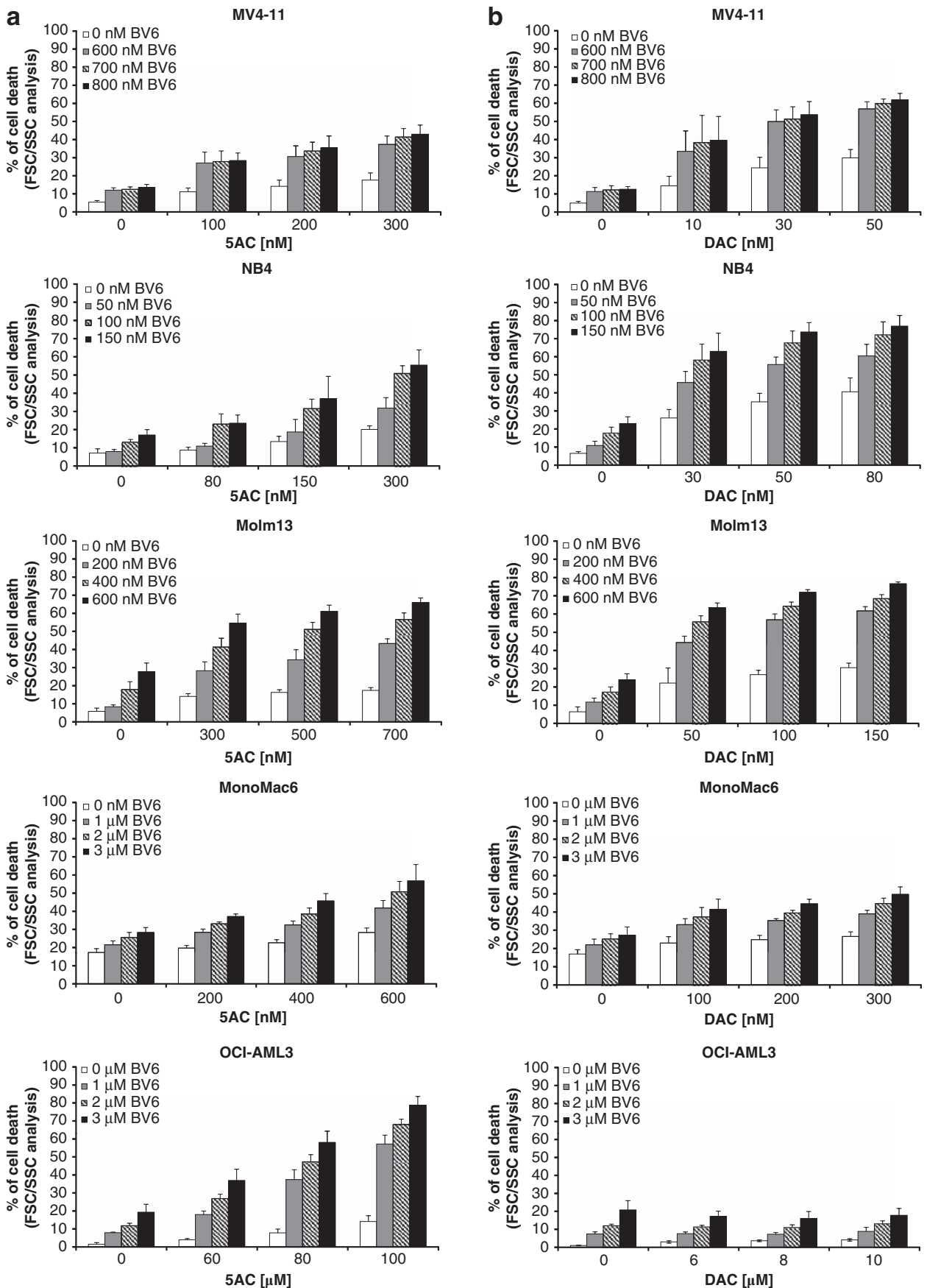

Figure 1 BV6 and demethylating agents synergize to induce cell death in AML cells. (a and $\mathbf{b}$ ) AML cells were treated for $72 \mathrm{~h}$ with indicated concentrations of BV6 and/or $5 A C(a)$ or DAC (b). Cell death was determined by FSC/SSC analysis and flow cytometry. Mean and SD of three experiments performed in triplicate are shown

As Smac mimetic has been reported to stimulate TNF $\alpha$ production, thereby initiating a TNF $\alpha$-driven autocrine/ paracrine loop to trigger cell death, ${ }^{14,21,22,30}$ we next investigated whether TNF $\alpha$ is involved in mediating BV6/ DAC-induced cell death. To address this question, we used the TNF $\alpha$-blocking antibody Enbrel to interfere with TNF $\alpha$ / TNFR1 signaling. Enbrel significantly decreased cell death upon cotreatment with BV6/DAC or monotherapy with BV6 in MV4-11 cells, whereas it had no effect in NB4 cells (Figure 3b). By comparison, Enbrel inhibited cell death in both MV4-11 and NB4 cells upon cotreatment with TNF $\alpha$ and BV6 that was used as a positive control to demonstrate that Enbrel is able to block TNF $\alpha$-mediated cell death (Supplementary Figure 1). Consistently, treatment with BV6/DAC significantly increased TNF $\alpha$ mRNA levels in MV4-11 but not in NB4 cells (Figure 3c). This set of experiments indicates that BV6/DAC-induced cell death partly depends on a TNF $\alpha$ autocrine/paracrine loop in MV4-11 cells, whereas it occurs independently of TNF $\alpha$ in NB4 cells. 

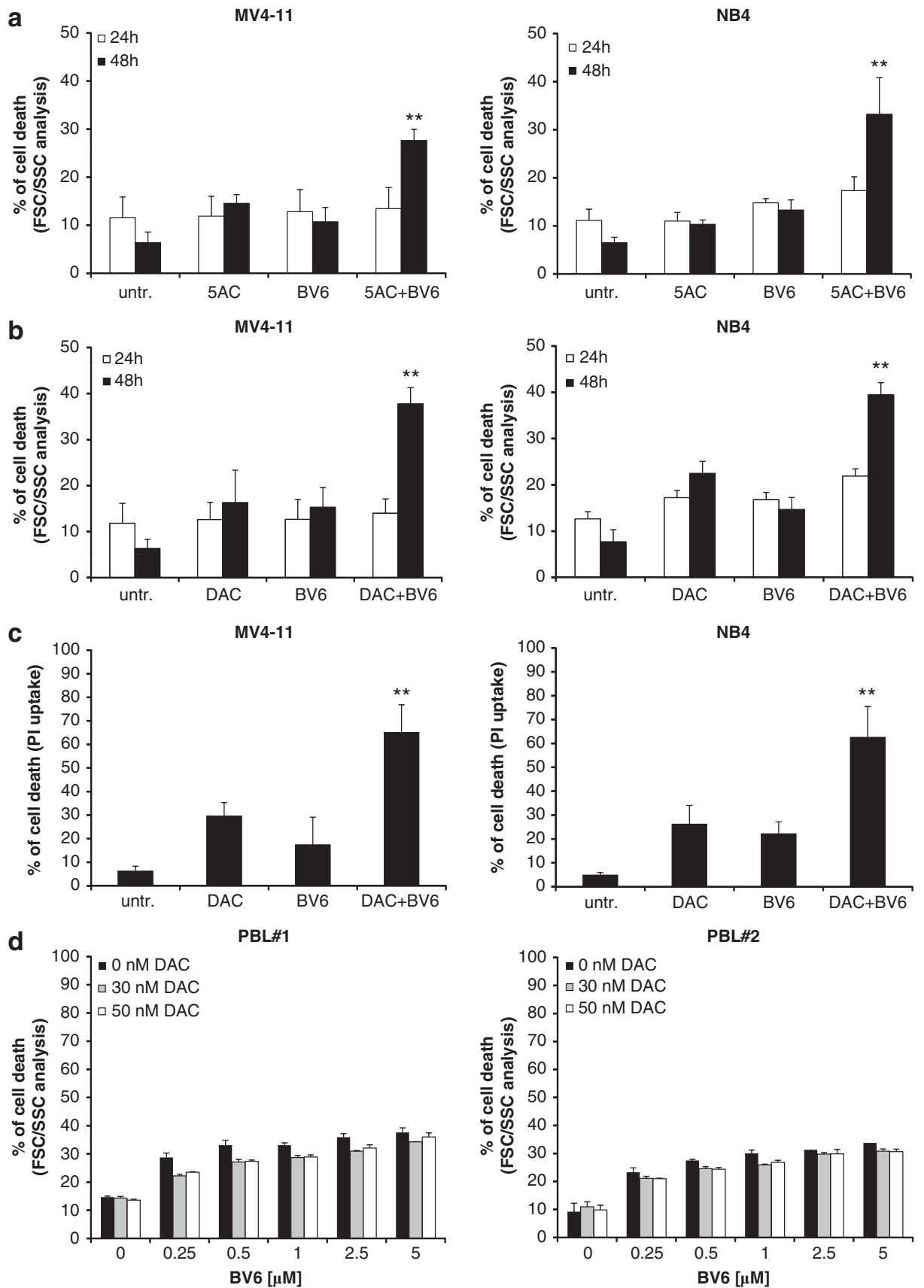

Figure 2 BV6 and demethylating agents cooperate to induce cell death in AML cells but not in PBLs. (a and $\mathbf{b})$ MV4-11 and NB4 cells were treated for 24 or $48 \mathrm{~h}$ with indicated concentrations of BV6 and/or 5AC (a) or DAC (b). Cell death was determined by FSC/SSC analysis and flow cytometry. Mean and SD of three experiments performed in triplicate are shown. ${ }^{* *} P<0.01$ comparing cells treated with BV6/5AC or BV6/DAC with control cells. (c) MV4-11 and NB4 cells were treated for $72 \mathrm{~h}$ with BV6 and/or DAC (MV4-11: $600 \mathrm{nM}$ BV6, $30 \mathrm{nM}$ DAC; NB4: $100 \mathrm{nM} \mathrm{BV6,50} \mathrm{nM} \mathrm{DAC).} \mathrm{Cell} \mathrm{death} \mathrm{was} \mathrm{determined} \mathrm{by} \mathrm{PI} \mathrm{uptake.} \mathrm{Mean} \mathrm{and} \mathrm{SD} \mathrm{of} \mathrm{three} \mathrm{experiments} \mathrm{performed} \mathrm{in}$ triplicate are shown. ${ }^{* *} P<0.01$ comparing cells treated with BV6/DAC with control cells. (d) PBLs were treated for $48 \mathrm{~h}$ with indicated concentrations of BV6 and/or DAC. Apoptosis was determined by FSC/SSC analysis and flow cytometry. Mean and SD of one experiment in triplicate are shown, each experiment was performed with a PBL preparation of an individual donor (PBL\#1, PBL\#2)

BV6 and DAC cooperate to induce caspase activation, mitochondrial perturbations and DNA fragmentation. To investigate whether cells die via apoptotic cell death, we determined DNA fragmentation as a biochemical hallmark of apoptosis. Indeed, BV6 together with 5AC or DAC cooperated to trigger DNA fragmentation compared with either agent alone (Figure 4a). As the mitochondrial pathway of apoptosis has been implied in DAC-induced apoptosis, ${ }^{31}$ we next examined mitochondrial events. Interestingly, we found that cotreatment with BV6 and DAC significantly increased the percentage of cells with hyperpolarization of the mitochondrial membrane potential (MMP) in a time-dependent manner, which was associated with a loss of MMP in BV6/DAC-cotreated cells (Figure 4b). 
a

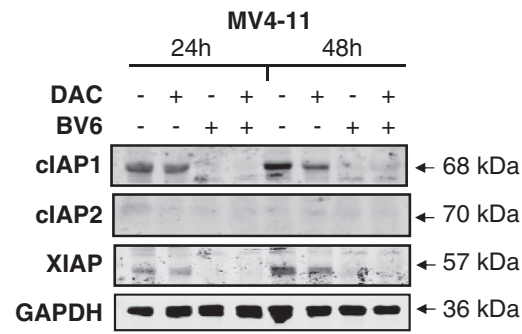

b

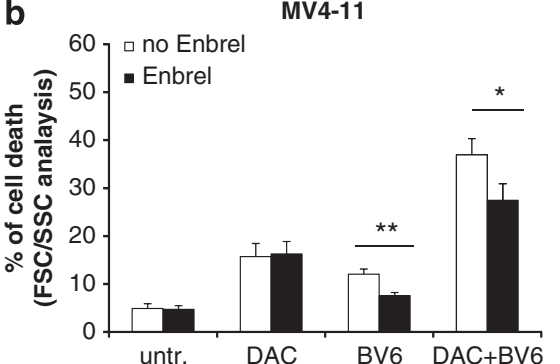

c

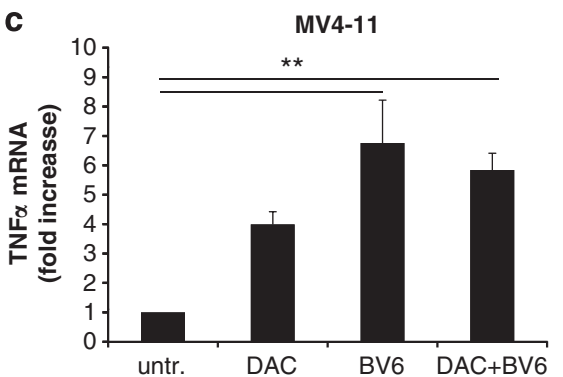

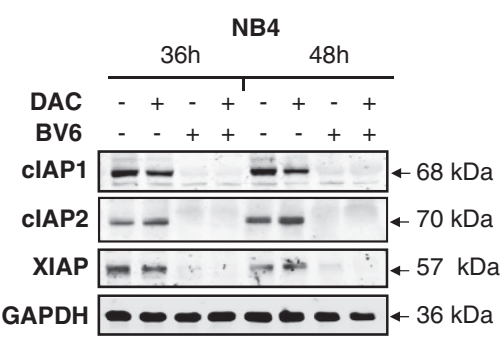

NB4

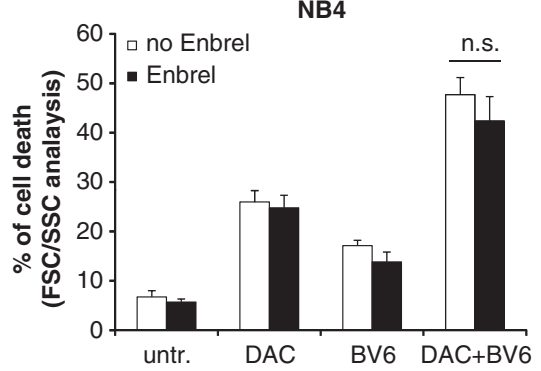

NB4

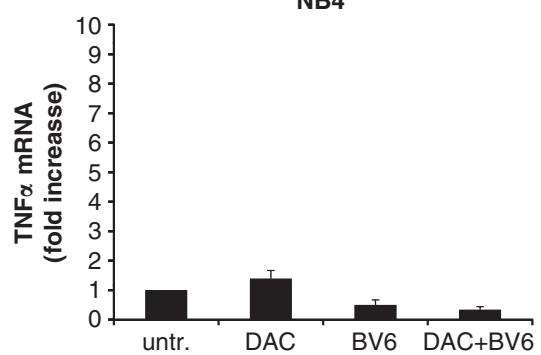

Figure 3 BV6/DAC-induced cell death is partly TNF $\alpha$-dependent. (a) Cells were treated for 24 and $48 \mathrm{~h}$ (MV4-11) or for 36 and $48 \mathrm{~h}$ (NB4) with BV6 and/or DAC (MV4-11:

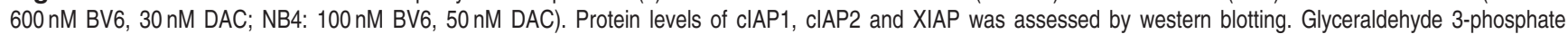
dehydrogenase (GAPDH) was used as loading control. (b) MV4-11 and NB4 cells were treated for $48 \mathrm{~h}$ with BV6 and/or DAC in the presence or absence of $100 \mu \mathrm{g} / \mathrm{ml}$ Enbrel. Cell death was determined by FSC/SSC analysis. Mean and SD of three experiments performed in triplicate are shown. ${ }^{*} P<0.05$; ${ }^{* \star} P<0.01$; n.s., not significant. (c) MV4-11 and NB4 cells were treated for $24 \mathrm{~h}$ with BV6 and/or DAC. TNF $\alpha$ mRNA levels were determined by qRT-PCR and are shown as fold increase. Mean and SD of three experiments performed in triplicate are shown. ${ }^{*} P<0.01$

This BV6/DAC-stimulated hyperpolarization of MMP preceded the loss of the MMP at 48h in MV4-11 (Figure 4b). B-cell lymphoma 2 (Bcl-2) overexpression significantly reduced BV6/DAC-induced cell death in MV4-11 but not in NB4 cells, whereas it prevented MegaFas ligand (MFL)-induced cell death in both cell lines, which was used as positive control (Figures $4 \mathrm{c}$ and $\mathrm{d}$ ).

We also monitored the activation of the caspase cascade by western blotting as an additional characteristic feature of apoptosis. BV6 acted in concert with DAC to trigger processing of caspase- 9 and -3 into active cleavage fragments as indicated by an increase in the caspase- 9 cleavage fragments p37/35 and the caspase-3 cleavage products p19/17/12 (Figure 4e). Moreover, there was a slight increase in active caspase- 8 cleavage products $p 43 / 41$ or decreased levels of the proenzyme form of caspase- 8 (Figure 4e), consistent with some activation of caspase- 8 by BV6/DAC cotreatment. These results demonstrate that BV6 and DAC cooperate to trigger typical apoptotic events, including mitochondrial perturbations, caspase activation and DNA fragmentation.
BV6/DAC cotreatment triggers caspase-independent cell death in apoptosis-resistant AML cells. Next, we tested the requirement of caspases for cell death induction by using the broad-range caspase inhibitor zVAD.fmk. Surprisingly, zVAD.fmk failed to protect MV4-11 cells against BV6/DAC-induced cell death (Figure 5a), although BV6/DAC cotreatment induced caspase activation in these cells (Figure 4c). Similarly, no rescue of BV6/DAC-triggered cell death by zVAD.fmk was found in Molm13 and MonoMac6 cells (Figure 5a). In fact, the addition of zVAD.fmk even significantly increased BV6/DACinduced cell death in MV4-11, Molm13 and MonoMac6 cells (Figure 5a). In NB4 cells, zVAD.fmk significantly reduced BV6/DAC-induced cell death (Figure 5a). Moreover, MFLmediated cell death that was used as a positive control for caspase-dependent apoptosis was significantly decreased by $z$ VAD.fmk in all AML cell lines (Figure 5a). These findings indicate that BV6/DAC cotreatment triggers caspase-independent cell death in the majority of AML cell lines when caspase activation is blocked.

As caspase inhibition has been reported to cause a switch from apoptosis to necroptosis, ${ }^{11}$ we asked whether 
a

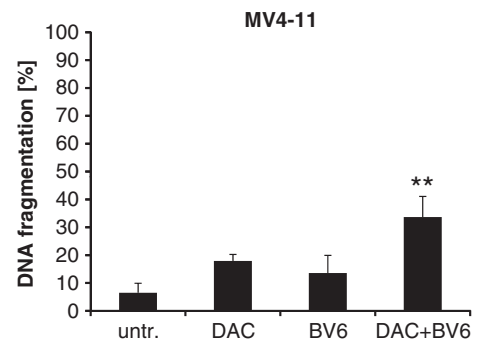

b

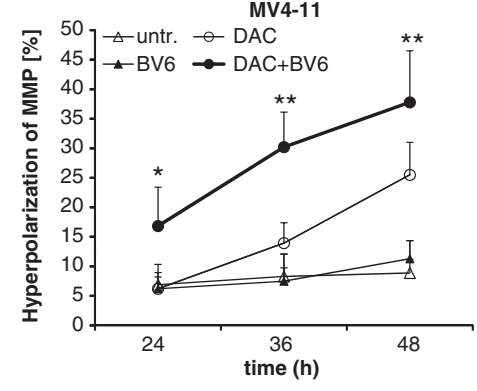

MV4-11

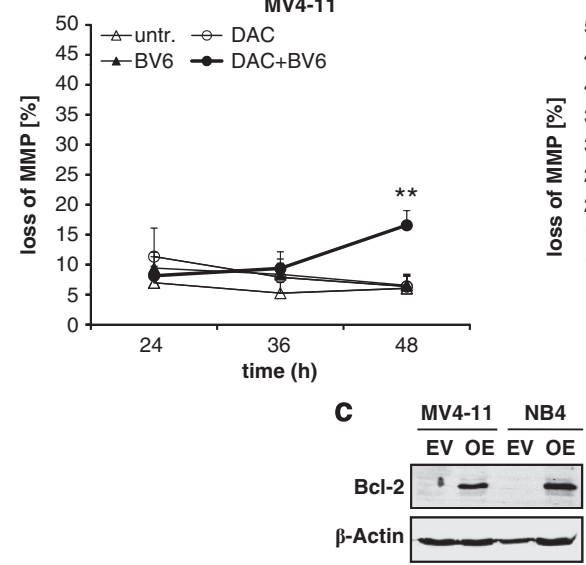

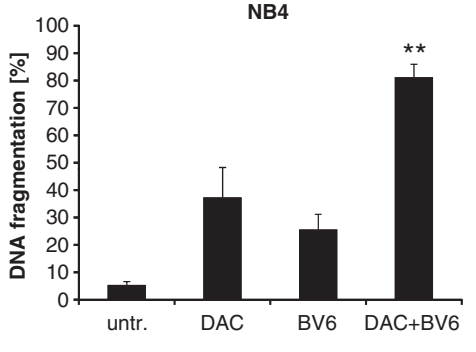
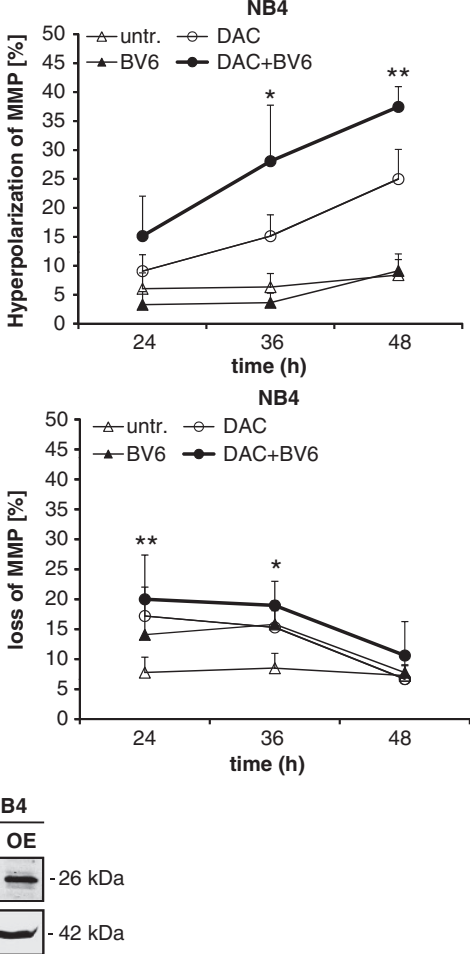

d
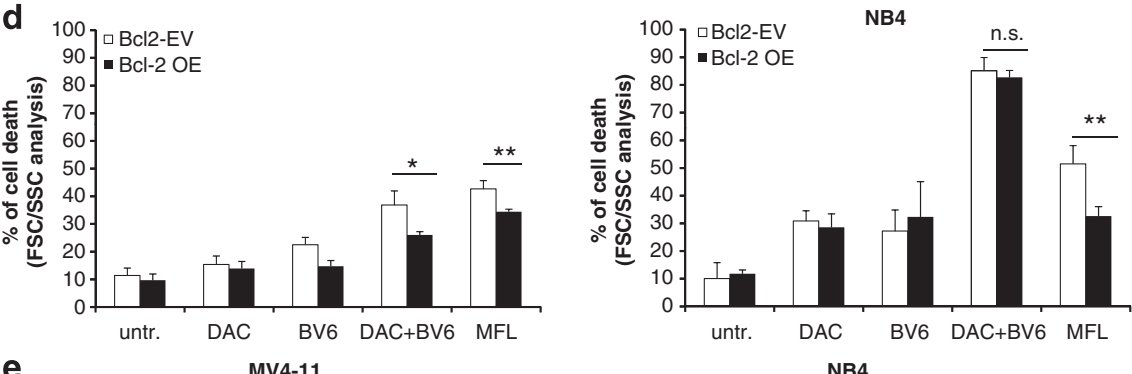

e
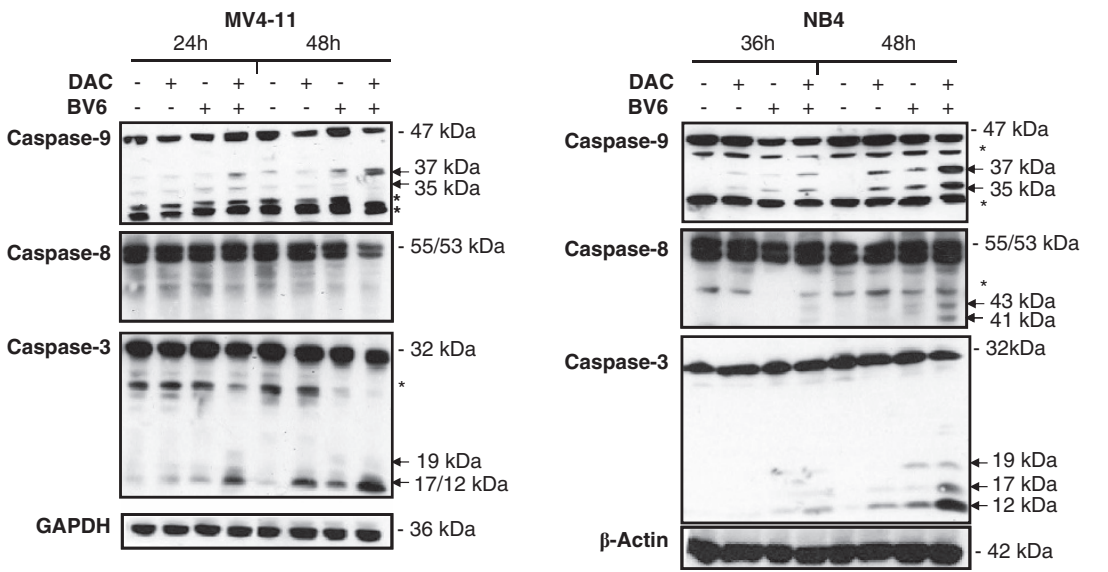
BV6/DAC-treated AML cells undergo necroptotic cell death in the presence of zVAD.fmk. To address this question, we simultaneously monitored phosphatidylserine exposure on the plasma membrane by Annexin- $V$ staining as a typical marker of apoptosis in parallel with PI staining to determine the loss of plasma membrane integrity as an early marker of necroptosis. Interestingly, the addition of zVAD.fmk to BV6/ DAC-treated cells significantly enhanced the percentage of Annexin-V/PI double-positive cells (Figures $5 \mathrm{~b}$ and $\mathrm{c}$ ), which is in line with our results obtained by forward/side scatter (FSC/SSC) analysis (Figure 5a). These findings underscore that $z V A D$.fmk is unable to protect $A M L$ cells from undergoing caspase-independent cell death upon BV6/DAC cotreatment and point to a switch from apoptotic to non-apoptotic cell death upon caspase inhibition.

BV6/DAC combination treatment bypasses apoptosis resistance via a switch to necroptosis. As the generation of reactive oxygen species (ROS) has been implicated in necroptotic cell death, ${ }^{9}$ we next investigated the question whether ROS is produced in BV6/DAC-treated AML cells upon caspase inhibition. Interestingly, we found increased production of ROS in BV6/DAC-treated MV4-11 cells in the presence and not in the absence of zVAD.fmk (Figure 6a), corresponding to increased cell death of BV6/DAC-treated MV4-11 cells on the addition of zVAD.fmk (Figure 5a). In contrast, no increased ROS generation was detected on the addition of zVAD.fmk to BV6/DAC-treated NB4 cells (Figure 6a), consistent with the failure of zVAD.fmk to enhance BV6/DAC-mediated cell death in NB4 cells (Figure 5a). To explore whether this ROS generation is required for cell death induction, we used $\mathrm{N}$-acetyl-cysteine (NAC), a scavenger of oxygen-free radicals. Importantly, preincubation of MV4-11 cells with NAC significantly reduced BV6/DAC-induced cell death in the presence of zVAD.fmk (Figure $6 \mathrm{~b}$ ), indicating that ROS production contributes to BV6/DAC-induced caspase-independent cell death in MV4-11 cells.

To further explore the hypothesis that AML cells switch from apoptosis to necroptosis on the addition of zVAD.fmk, we used pharmacological inhibitors to block key components of necroptosis signaling. To this end, we used the RIP1 kinase inhibitor necrostatin-1 (Nec-1), as RIP1 is a critical mediator of necroptosis. ${ }^{9}$ Intriguingly, simultaneous treatment with both Nec-1 and zVAD.fmk significantly reduced BV6/DAC-induced cell death compared with cells that were treated with BV6/ DAC in the presence of zVAD.fmk, but without Nec-1 (Figure 6c). These findings demonstrate that RIP1 kinase activity is required for BV6/DAC-induced cell death in AML cells when caspase activation is prevented, thus confirming a switch from apoptosis to necroptosis upon caspase inhibition. By comparison, co-addition of $\mathrm{Nec}-1$ and zVAD.fmk reduced BV6/DAC-induced cell death to a similar extent than zVAD.fmk alone in NB4 cells (Figure 6c). This shows that RIP1 kinase activity is dispensable for BV6/DAC-induced cell death in the presence of zVAD.fmk in NB4 cells.

As MLKL has recently been discovered as a novel component of the necroptotic machinery, ${ }^{10}$ we used necrosulfonamide (NSA), a pharmacological inhibitor of MLKL, ${ }^{10}$ to further test the hypothesis that $A M L$ cells die via necroptosis. Of note, NSA significantly decreased BV6/ DAC-induced cell death in MV4-11 cells in the presence of both NSA and zVAD.fmk compared with BV6/DAC-treated cells in the presence of zVAD.fmk, but without NSA (Figure 6d). Similarly, NSA significantly reduced BV6/DACtriggered cell death in the presence of zVAD.fmk in Molm13 cells (Figure $6 \mathrm{~d}$ ). These experiments using pharmacological inhibitors of necroptosis signaling confirm that BV6/DACcotreated AML cells switch from apoptosis to necroptosis when caspase activation is blocked.

\section{Discussion}

Defects in cell death programs, including the overexpression of IAP proteins, contribute to treatment resistance and poor outcome in AML. ${ }^{32}$ Therefore, novel approaches are necessary to shift the balance towards cell death in AML. Here we demonstrate for the first time that the Smac mimetic BV6 acts in concert together with demethylating agents, such as $5 \mathrm{AC}$ and DAC, to trigger cell death in AML cells. This interaction occurs in a highly synergistic manner as demonstrated by the calculation of $\mathrm{Cl}$ underlining the potency of this combination approach. Importantly, we show that BV6/DAC combination therapy is even effective in a model of apoptosis resistance via a switch in the type of cell death from BV6/DAC-induced apoptosis to necroptosis.

This conclusion is supported by the following independent lines of evidence: First, the broad-range caspase inhibitor zVAD.fmk fails to rescue BV6/DAC-induced cell death, demonstrating that $z V A D$.fmk is unable to protect $A M L$ cells from undergoing a caspase-independent cell death. Second, the addition of zVAD.fmk increases the percentage of Annexin-V/PI double-positive cells, pointing to a shift in the mode of cell death from apoptosis to necroptosis. This finding is in line with recent evidence demonstrating that apoptotic and necroptotic signaling pathways are tightly interconnected. For example, caspase activity has been shown to negatively regulate necroptosis by cleaving RIP1, one of the critical regulators of necroptosis. ${ }^{11}$ This implies that necroptosis serves as a fail-safe and even more efficient cell death

Figure 4 BV6 and DAC cooperate to trigger caspase activation, mitochondrial perturbations and DNA fragmentation. (a) MV4-11 and NB4 cells were treated for $72 \mathrm{~h}$ with indicated concentrations of BV6 and/or DAC (MV4-11: $600 \mathrm{nM} \mathrm{BV6,} 30 \mathrm{nM}$ DAC; NB4: $100 \mathrm{nM}$ BV6, $50 \mathrm{nM} \mathrm{DAC).} \mathrm{Apoptosis} \mathrm{was} \mathrm{determined} \mathrm{by} \mathrm{fluorescence-activated} \mathrm{cell}$ sorting analysis of DNA fragmentation of Pl-stained nuclei. Mean and SD of three experiments performed in triplicate are shown. ${ }^{*} P<0.05$; ${ }^{* *} P<0.01$ comparing cells treated with BV6/DAC with control cells. (b) MV4-11 and NB4 cells were treated for indicated times with BV6 and/or DAC (MV4-11: 600 nM BV6, 30 nM DAC; NB4: $100 \mathrm{nM}$ BV6, $50 \mathrm{nM}$ DAC). MMP was assessed by FACS analysis and hyperpolarization of MMP (upper panels) and loss of MMP (lower panels) are shown. Mean and SD of three experiments performed in triplicate are shown. ${ }^{*} P<0.05 ;{ }^{*} P<0.01$ comparing cells treated with BV6/DAC with control cells. (c and d) Cells were transduced with murine Bcl-2. Expression of murine Bcl-2 was analyzed by western blotting (c) and cell death was determined by FSC/SSC analysis after treatment for $48 \mathrm{~h}$ with BV6 and/or DAC (MV4-11: $600 \mathrm{nM}$ BV6, $30 \mathrm{nM}$ DAC; NB4: $100 \mathrm{nM} \mathrm{BV6,} 50 \mathrm{nM}$ DAC). Mean and SD of three experiments performed in triplicate are shown; ${ }^{*} P<0.05 ;{ }^{* \star} P<0.01 ; n .5$., not significant. (e) Cells were treated for 24 and $48 \mathrm{~h}$ (MV4-11) or for 36 and $48 \mathrm{~h}$ (NB4) with BV6 and/or DAC (MV4-11: $600 \mathrm{nM}$ BV6, $30 \mathrm{nM}$ DAC; NB4: 100 nM BV6, 50 nM DAC). Caspase activation was analyzed by western blotting. Arrowheads indicate caspase cleavage fragments; the asterisks mark unspecific bands 

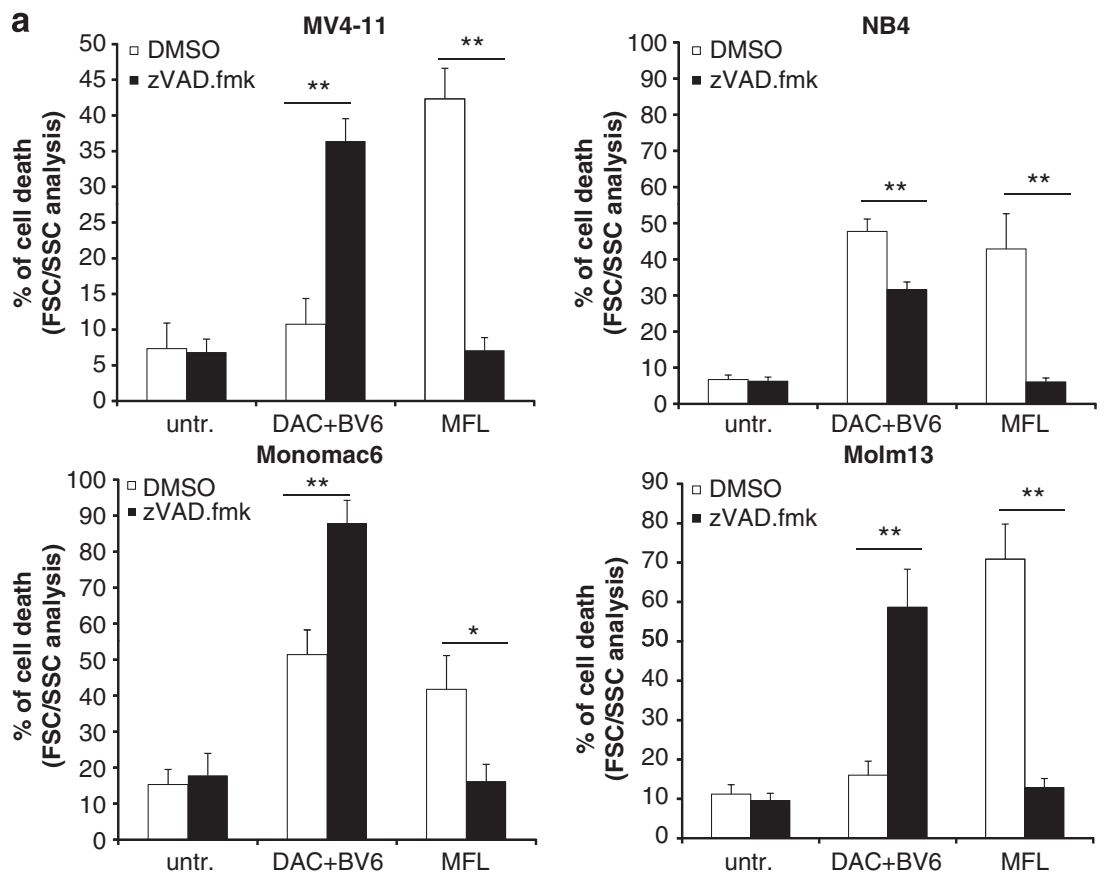

b
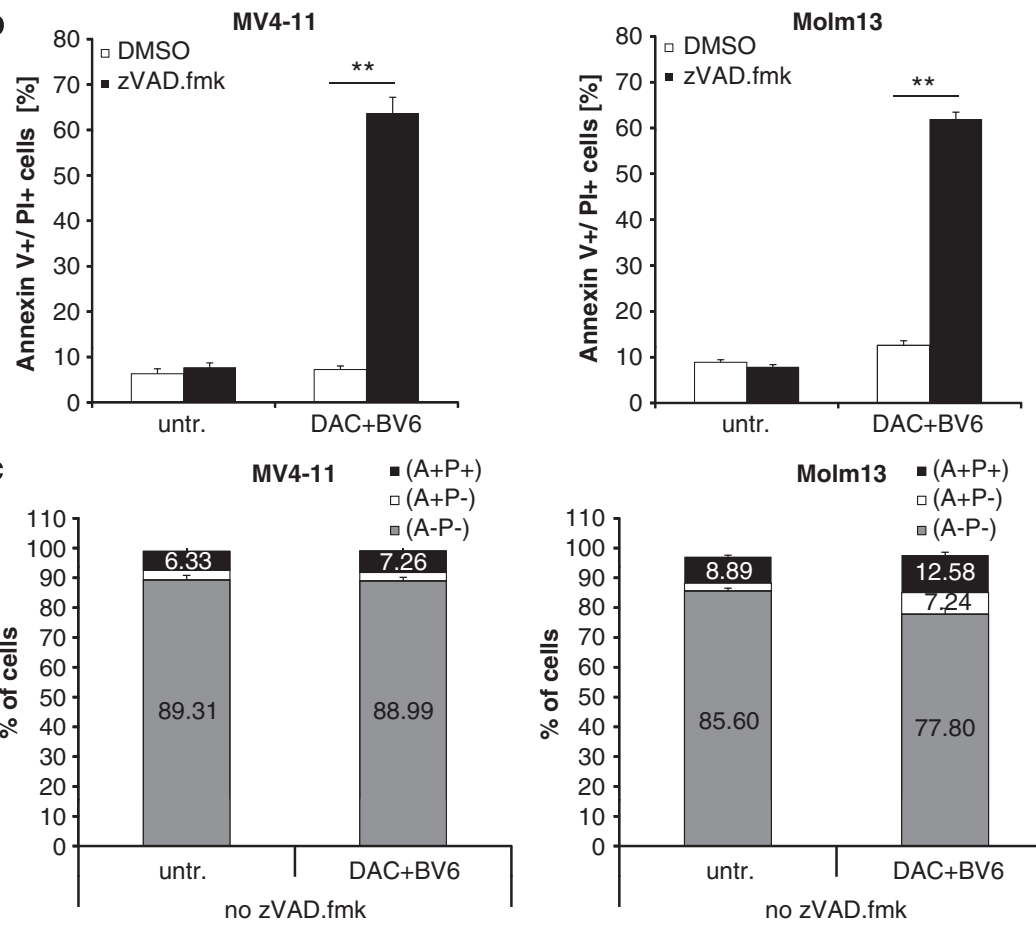

C
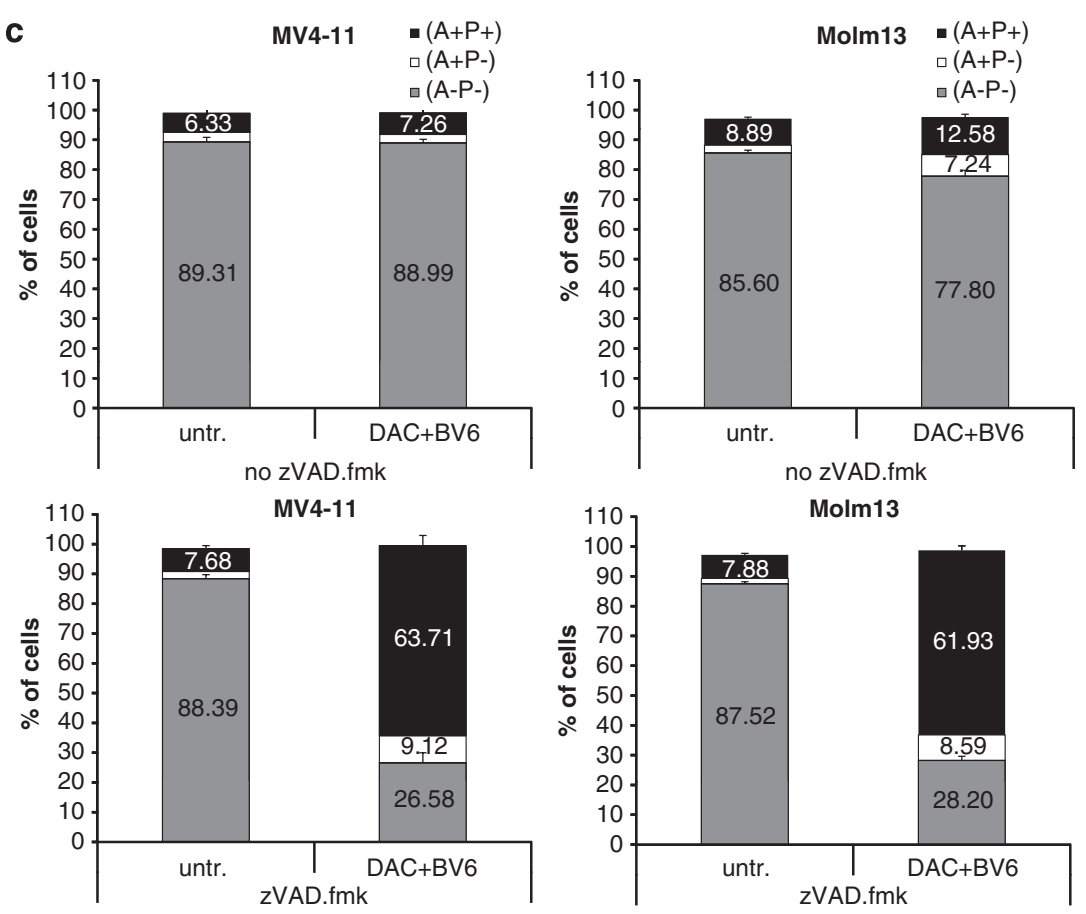
program, especially under conditions when caspase activation is blocked. In line with this notion, BV6/DAC-induced necroptosis upon caspase inhibition turned out, in our study, to be more efficient than BV6/DAC-mediated apoptosis. Third, BV6/DAC-induced cell death upon caspase inhibition depends on an intact necroptotic signal transduction pathway, as the pharmacological inhibition of key components of necroptosis, including RIP1 kinase (by using Nec-1) or MLKL (by using NSA), significantly reduces BV6/DAC-induced cell death in zVAD.fmk-treated AML cells. Together, these pieces of evidence support the hypothesis that BV6- and DACinduced cell death switches from apoptosis to necroptosis upon caspase inhibition. Thus, in apoptosis-proficient AML cells (i.e., in the absence of zVAD.fmk), BV6/DAC combination therapy primarily induces caspase-dependent apoptosis. Alternatively, in a model of apoptosis resistance (i.e., in the presence of zVAD.fmk), treatment with BV6/DAC engages caspase-independent necroptosis. We found this switch in BV6/DAC-induced cell death in three of four AML cell lines that were tested in this study (MV4-11, Molm13 and MonoMac6 cells), indicating that it is a frequent event in AML. However, as these results also point to some heterogeneity among AML cell lines, future studies are required to elucidate the molecular basis of this differential response.

The novelty of the current study is in particular due to the following two points: first, we show that the Smac mimetic BV6 primes AML cells in a synergistic fashion for demethylating agents that are currently investigated as experimental drugs in clinical trials for the treatment of AML. ${ }^{27}$ There is increasing evidence that IAP proteins represent promising targets for therapeutic intervention in AML. ${ }^{32}$ Previously, a correlation between elevated XIAP protein levels in AML samples and poor outcome has been reported. ${ }^{16,17}$ Moreover, clAP2 was found to be part of a three-gene expression signature that was associated with poor overall survival in AML. ${ }^{18}$ In CBF AML, deregulated apoptotic signaling and high IAP protein levels were linked to a poor prognostic subgroup that was identified by gene expression profiling. ${ }^{19}$ In corresponding in vitro studies, we recently demonstrated that CBF AML cell lines, as well as primary samples from newly diagnosed CBF AML patients that belong to the subgroup with superior outcome, also display an increased sensitivity to treatment with BV6. ${ }^{20}$ As for rational combinations with Smac mimetic in AML, Smac mimetic has so far been tested together with classical chemotherapeutic agents (i.e., cytarabine, etoposide and doxorubicin), tyrosine kinase inhibitors, including the Fms-like tyrosine kinase 3 inhibitor PKC412, and the BCR-ABL inhibitors imatinib and nilotinib, or the death receptor ligand TRAIL. ${ }^{33-36}$ However, there are no studies yet testing Smac mimetic together with epigenetic drugs, such as demethylating agents, which underscores the novelty of our study. Mechanistically, both BV6 and DAC cause downregulation of CIAP1 and XIAP, and also cooperated to further decrease XIAP levels, which may contribute to their synergistic induction of cell death in AML cells. The suppression of cIAP1 and XIAP by DAC has previously been observed and has been linked to DAC-mediated inhibition of $N F-\kappa B$ activation. $^{37,38}$

Second, we demonstrate for the first time that the combination of Smac mimetic and demethylating agents can even overcome the resistance of apoptosis-deficient AML cells by engaging necroptosis as an alternative type of cell death. There is mounting evidence that Smac mimetic not only promotes apoptosis, but can also increase the sensitivity towards the induction of necroptosis under certain conditions, especially when the execution of cell death via apoptosis is blocked. We previously reported that the Smac mimetic BV6 bypasses apoptosis resistance in FADD- or caspase-8deficient ALL cells or in fibrosarcoma cells by engaging necroptosis. ${ }^{39,40}$ Against this background, the present study is the first to demonstrate that Smac mimetic acts together with demethylating drugs to trigger necroptosis in apoptosisresistant $A M L$ cells. At present, very little is known about the relevance of necroptosis as an alternative mode of cell death in AML. There is only one previous report showing that an AML-targeted diphtheria toxin triggers caspase-independent necroptosis in AML cells in addition to caspase-dependent apoptosis. ${ }^{41}$ Thus, necroptosis represents a promising novel approach for further therapeutic exploitation in AML.

Our data have several important implications for developing Smac mimetic-based combination treatments for AML. First, by demonstrating that Smac mimetic synergizes with demethylating drugs to induce cell death in AML cells, our study sets the ground for further evaluation of this combination strategy for the treatment of AML. Epigenetic drugs, including demethylating agents, are among the promising experimental compounds that are currently tested in early clinical trials for AML, ${ }^{27}$ underlining the clinical relevance of such a combination regimen. Clinically achievable plasma concentrations have been reported to range from 3 to $11 \mu \mathrm{M}$ for $5 \mathrm{AC}$ and from 0.3 to $1.6 \mu \mathrm{M}$ for $\mathrm{DAC},{ }^{42-44}$ indicating that concentrations of $5 \mathrm{AC}$ and DAC required for synergism with BV6 might be achievable in the body.

Second, Smac mimetic may be used in combination protocols to reduce the dose of demethylating drugs that is required for antileukemic activity. Both classes of compounds yielded a highly synergistic effect when used at concentrations that exerted little cytotoxicity as single agent. Third, the combination strategy of Smac mimetic plus demethylating agents may open new perspectives to tackle apoptosis resistance in AML, as it can engage an alternative cell death

Figure 5 BV6/DAC cotreatment induces caspase-independent cell death in apoptosis-resistant AML cells. (a) AML cells were treated for 48 $\mathrm{h}$ (NB4, MonoMac6) or $6 \mathrm{~h}$ (MV4-11, Molm-13) with BV6 and DAC in the presence or absence of $20 \mu \mathrm{M}$ zVAD.fmk (MV4-11: $600 \mathrm{nM} \mathrm{BV6,30} \mathrm{nM} \mathrm{DAC;} \mathrm{NB4:} \mathrm{100} \mathrm{nM} \mathrm{BV6,} 50$ nM DAC; Molm13: 400 nM BV6, $100 \mathrm{nM}$ DAC; MonoMac6: $3 \mu \mathrm{M}$ BV6, $300 \mathrm{nM} \mathrm{DAC);} \mathrm{treatment} \mathrm{with} 40 \mathrm{ng} / \mathrm{ml}$ MFL, a hexameric form of CD95 ligand, for $48 \mathrm{~h}$ served as positive control. Cell death was determined by FSC/SSC analysis. Mean and SD of three experiments performed in triplicate are shown; ${ }^{*} P<0.05$; ${ }^{* *} P<0.01$. (b and $\mathbf{c}$ ) AML cells were treated for $6 \mathrm{~h}$ with BV6 and DAC in the presence or absence of $20 \mu \mathrm{M}$ zVAD.fmk (MV4-11: $600 \mathrm{nM}$ BV6, $30 \mathrm{nM}$ DAC; Molm13: $400 \mathrm{nM}$ BV6, 100 nM DAC). Cell death was determined by Annexin-V/PI staining and fluorescence-activated cell sorting analysis. The percentage of Annexin-V positive/PI double-positive cells is shown (b) with mean and SD of three experiments performed in triplicate; ${ }^{*} P<0.01$. In c, the percentage of Annexin-V (A)- and/or PI (P)-positive and -negative cells is shown with mean and SD of three experiments performed in triplicate 

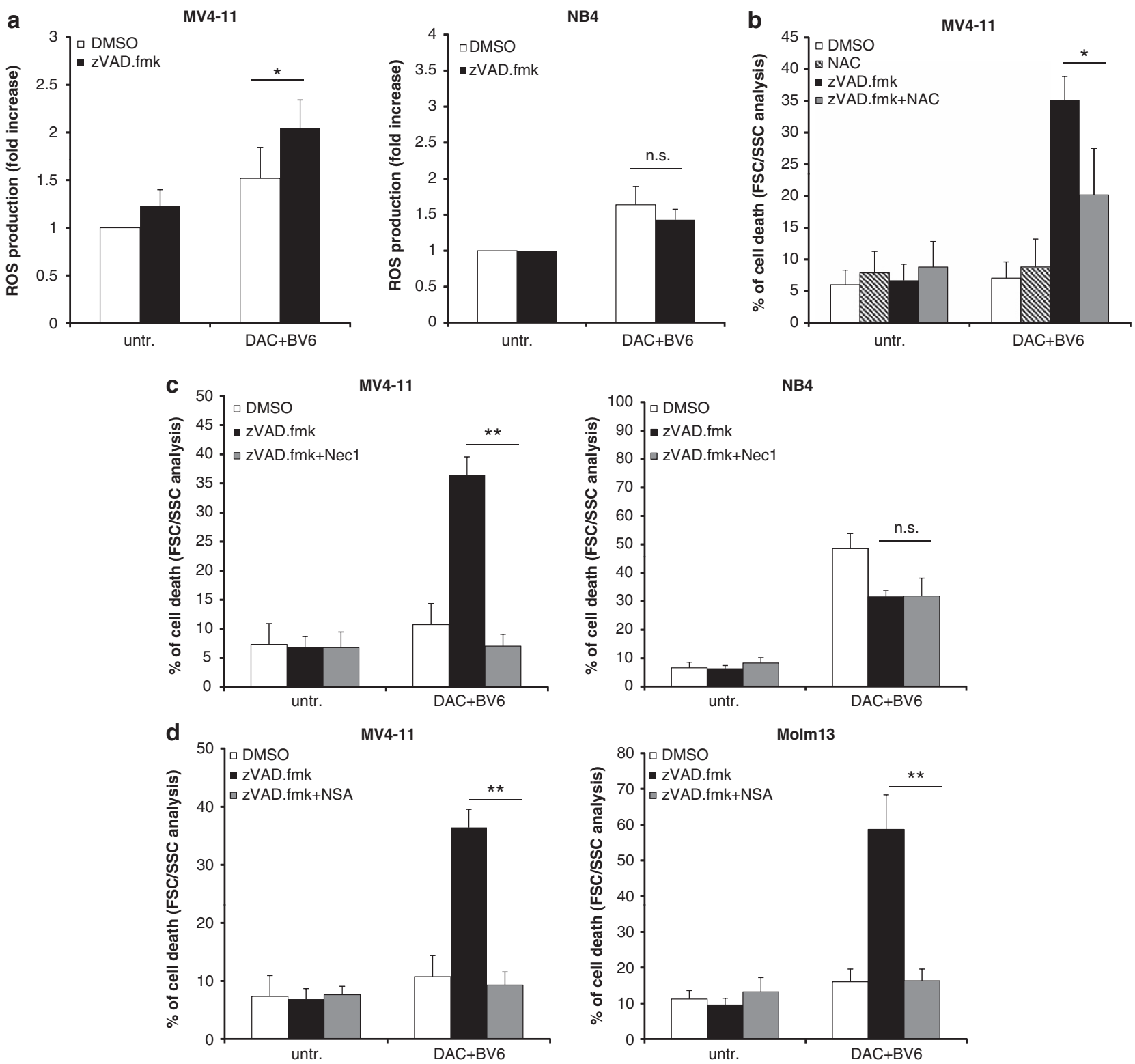

Figure 6 BV6/DAC combination treatment bypasses apoptosis resistance via a switch to necroptosis. (a) Cells were treated for $6 \mathrm{~h}$ (MV4-11) or 48 $\mathrm{h}$ (NB4) with BV6 and DAC (MV4-11: $600 \mathrm{nM}$ BV6, $30 \mathrm{nM}$ DAC; NB4: $100 \mathrm{nM}$ BV6, $50 \mathrm{nM}$ DAC) in the presence or absence of $20 \mu \mathrm{M}$ zVAD.fmk. ROS production was determined by CellROX staining and flow cytometry, and is shown as fold increase. (b) MV4-11 cells were treated for $6 \mathrm{~h}$ with BV6 and DAC (MV4-11:600 nM BV6, 30 nM DAC) in the presence or absence of $20 \mu \mathrm{M}$ zVAD.fmk with or without pretreatment with $10 \mathrm{mM} \mathrm{NAC}$ for $24 \mathrm{~h}$. Cell death was determined by FSC/SSC and fluorescence-activated cell sorting analysis. (c and d) Cells were treated for $6 \mathrm{~h}$ (MV4-11, Molm13) or $48 \mathrm{~h}$ (NB4) with BV6 and DAC (MV4-11: $600 \mathrm{nM} \mathrm{BV6,} 30 \mathrm{nM}$ DAC; NB4: 100 nM BV6, $50 \mathrm{nM}$ DAC; Molm13: $400 \mathrm{nM}$ BV6, $100 \mathrm{nM} \mathrm{DAC}$ ) in the presence of $20 \mu \mathrm{M}$ zVAD.fmk and/or $30 \mu \mathrm{M} \mathrm{Nec}-1$ (c), or $1 \mu \mathrm{M} \mathrm{NSA}$ (d). Cell death was determined by FSC/SSC and FACS analysis. Mean and SD of at least three experiments performed in triplicate are shown; ${ }^{*} P<0.05 ;{ }^{* \star} P<0.01$; n.s., not significant

program, namely necroptosis, in apoptosis-resistant AML cells. As the evasion of apoptosis frequently occurs in AML and is considered to limit the success of current antileukemic therapies, ${ }^{32}$ innovative approaches to circumvent apoptosis resistance are urgently required. Fourth, the combination treatment with Smac mimetic and demethylating drugs may offer a tumor-selective antileukemic approach, as Smac mimetic did not sensitize normal PBLs for demethylating agents in contrast to malignant AML cells. Beyond AML, the identification of the synergistic interaction of Smac mimetic with demethylating agents has also broader implications for other types of cancer, as epigenetic changes are frequently found in human cancers and epigenetic modifiers constitute an emerging treatment modality of increasing relevance in various cancer entities. As IAP inhibitors, including Smac mimetic, are currently under investigation in early clinical trials, $^{12}$ it is a timely question to develop combination protocols with these compounds to exploit synergistic drug actions. In conclusion, Smac mimetic in combination with demethylating agents presents a promising new strategy to trigger cell death in AML, which warrants further exploitation. 


\section{Materials and Methods}

Cell culture and chemicals. AML cell lines were obtained from ATCC (CEM, Manassas, VA, USA) or DSMZ (Braunschweig, Germany) and were cultured in RPMI 1640 or Dulbecco's modified Eagle medium (Life Technologies, Inc., Eggenstein, Germany), supplemented with $10 \%$ fetal calf serum (FCS; Biochrom, Berlin, Germany), $1 \mathrm{mM}$ glutamine (Invitrogen, Karlsruhe, Germany), $1 \%$ penicillin/streptomycin (Invitrogen) and $25 \mathrm{mM} \mathrm{HEPES} \mathrm{(Biochrom).} \mathrm{PBLs} \mathrm{were}$ isolated from buffy coats of healthy donors by ficoll separation (Biochrom) and were cultured in X-VIVO Medium (Lonza, Walkersville, MD, USA) supplemented with $10 \% \mathrm{FCS}$ and $1 \%$ penicillin/streptomycin. The study was approved by the local Ethical Committee. Smac mimetic BV6, which neutralizes XIAP, CIAP1 and cIAP2, ${ }^{21}$ was kindly provided by Genentech, Inc. (South San Francisco, CA, USA) The caspase inhibitor zVAD.fm) was obtained from Bachem (Heidelberg, Germany), TNF $\alpha$ and Nec-1 from Biomol (Hamburg, Germany), and5AC or DAC from Sigma (Steinheim, Germany), NSA from Toronto Research Chemicals Inc. (North York, CA, USA). Enbrel was kindly provided by Pfizer (Berlin, Germany). All chemicals were purchased by Sigma unless indicated otherwise. Cells were transduced with pMSCV vector containing mouse Bcl-2 or empty vector using Phoenix packaging cells (ATCC)

Western blot analysis. Western blot analysis was performed as described previously, ${ }^{45}$ using the following antibodies: caspase-8 (Alexis Biochemicals, Epalinges, Switzerland), caspase-3, caspase-9 (Cell Signaling, Beverly, MA USA), Bcl-2 (Invitrogen), XIAP (BD Biosciences, Heidelberg, Germany), clAP1 (R\&D Systems, Inc., Wiesbaden, Germany), clAP2 (Enzo, Loerrach, Germany), $\beta$-actin (Sigma), glyceraldehyde 3-phosphate dehydrogenase (Absave, Harrogate, UK) and secondary antibodies conjugated to horseradish peroxidase (Santa Cruz Biotechnology, Santa Cruz, CA, USA). Enhanced chemiluminescence was used for detection (Amersham Bioscience, Freiburg, Germany). All western blots shown are representative of at least three independent experiments.

Determination of cell death. Apoptosis was determined by fluorescenceactivated cell sorting analysis (FACScan; BD Biosciences) of DNA fragmentation of PI-stained nuclei as described previously. ${ }^{45}$ Cell death was assessed by FSC/ SSC analysis and flow cytometry as described previously, ${ }^{24}$ or by Annexin-V/PI staining (Roche Diagnostics, Mannheim, Germany) according to manufacturer's instructions.

Determination of MMP, ROS and quantitative RT-PCR. Cells were incubated with tetramethylrhodamine methyl ester $(50 \mathrm{nM}$; Invitrogen) for MMP analysis and CellROX ( $1 \mu \mathrm{M}$; Invitrogen) for ROS analysis by flow cytometry. TNF $\alpha$ mRNA levels were determined by qRT-PCR as previously described. ${ }^{46}$

Statistical analysis. Statistical significance was assessed by Student's $t$-test (two-tailed distribution, two-sample, unequal variance). Drug interactions were analyzed by the $\mathrm{Cl}$ method according to $\mathrm{Chou}^{47}$ using the CalcuSyn software (Biosoft, Cambridge, UK). $\mathrm{Cl}<0.9$ : synergism, 0.9-1.1: additivity and >1.1: antagonism.

\section{Conflict of Interest}

The authors declare no conflict of interest.

Acknowledgements. BV6 was kindly provided by Genentech Inc. This work has been partially supported by grants from the Deutsche Forschungsgemeinschaft, European Community, IAP VII (to SF) and the Deutsche Krebshilfe (to SF and LS).

1. Estey E, Dohner H. Acute myeloid leukaemia. Lancet 2006; 368: 1894-1907.

2. Schimmer AD. Apoptosis in leukemia: from molecular pathways to targeted therapies. Best Pract Res Clin Haematol 2008; 21: 5-11.

3. Fulda S. Cell death in hematological tumors. Apoptosis 2009; 14: 409-423.

4. Fulda S, Debatin KM. Extrinsic versus intrinsic apoptosis pathways in anticancer chemotherapy. Oncogene 2006; 25: 4798-4811.

5. Hanahan D, Weinberg RA. Hallmarks of cancer: the next generation. Cell 2011; 144: 646-674

6. Galluzzi L, Vitale I, Abrams JM, Alnemri ES, Baehrecke EH, Blagosklonny MV et al. Molecular definitions of cell death subroutines: recommendations of the Nomenclature Committee on Cell Death 2012. Cell Death Differ 2012; 19: 107-120.

7. Ashkenazi A. Targeting the extrinsic apoptosis pathway in cancer. Cytokine Growth Factor Rev 2008; 19: 325-331.
8. Kroemer G, Galluzzi L, Brenner C. Mitochondrial membrane permeabilization in cell death. Physiol Rev 2007; 87: 99-163.

9. Vandenabeele P, Galluzzi L, Vanden Berghe T, Kroemer G. Molecular mechanisms of necroptosis: an ordered cellular explosion. Nat Rev Mol Cell Biol 2010; 11: 700-714.

10. Sun L, Wang H, Wang Z, He S, Chen S, Liao D et al. Mixed lineage kinase domain-like protein mediates necrosis signaling downstream of RIP3 kinase. Cell 2012; 148: 213-227.

11. Oberst A, Dillon CP, Weinlich R, McCormick LL, Fitzgerald P, Pop C et al. Catalytic activity of the caspase-8-FLIP(L) complex inhibits RIPK3-dependent necrosis. Nature 2011; 471: 363-367.

12. Fulda S, Vucic D, Targeting IAP. proteins for therapeutic intervention in cancer. Nat Rev Drug Discov 2012; 11: 109-124.

13. Eckelman BP, Salvesen GS, Scott FL. Human inhibitor of apoptosis proteins: why XIAP is the black sheep of the family. EMBO Rep 2006; 7: 988-994.

14. Bertrand MJ, Milutinovic S, Dickson KM, Ho WC, Boudreault A, Durkin J et al. clAP1 and CIAP2 facilitate cancer cell survival by functioning as E3 ligases that promote RIP1 ubiquitination. Mol Cell 2008; 30: 689-700.

15. Varfolomeev E, Goncharov T, Fedorova AV, Dynek JN, Zobel K, Deshayes K et al. c-IAP1 and C-IAP2 are critical mediators of tumor necrosis factor alpha (TNFalpha)-induced NFkappaB activation. J Biol Chem 2008; 283: 24295-24299.

16. Tamm I, Kornblau SM, Segall H, Krajewski S, Welsh K, Kitada S et al. Expression and prognostic significance of IAP-family genes in human cancers and myeloid leukemias. Clin Cancer Res 2000; 6: 1796-1803.

17. Tamm I, Richter S, Scholz F, Schmelz K, Oltersdorf D, Karawajew L et al. XIAP expression correlates with monocytic differentiation in adult de novo AML: impact on prognosis. Hematol J 2004; 5: 489-495.

18. Hess CJ, Berkhof J, Denkers F, Ossenkoppele GJ, Schouten JP, Oudejans JJ et al. Activated intrinsic apoptosis pathway is a key related prognostic parameter in acute myeloid leukemia. J Clin Oncol 2007; 25: 1209-1215.

19. Bullinger L, Rucker FG, Kurz S, Du J, Scholl C, Sander S et al. Gene-expression profiling identifies distinct subclasses of core binding factor acute myeloid leukemia. Blood 2007; 110: $1291-1300$

20. Luck SC, Russ AC, Botzenhardt U, Paschka P, Schlenk RF, Dohner H et al. Deregulated apoptosis signaling in core-binding factor leukemia differentiates clinically relevant, molecular marker-independent subgroups. Leukemia 2011; 25: 1728-1738.

21. Varfolomeev E, Blankenship JW, Wayson SM, Fedorova AV, Kayagaki N, Garg P et al. IAP antagonists induce autoubiquitination of c-IAPs, NF-kappaB activation, and TNFalphadependent apoptosis. Cell 2007; 131: 669-681.

22. Vince JE, Wong WW, Khan N, Feltham R, Chau D, Ahmed AU et al. IAP antagonists target cIAP1 to induce TNFalpha-dependent apoptosis. Cell 2007; 131: 682-693.

23. Wang L, Du F, Wang $X$. TNF-alpha induces two distinct caspase-8 activation pathways. Cell 2008; 133: 693-703.

24. Fakler M, Loeder S, Vogler M, Schneider K, Jeremias I, Debatin KM et al. Small molecule XIAP inhibitors cooperate with TRAIL to induce apoptosis in childhood acute leukemia cells and overcome Bcl-2-mediated resistance. Blood 2009; 113: 1710-1722.

25. Loeder S, Drensek A, Jeremias I, Debatin KM, Fulda S. Small molecule XIAP inhibitors sensitize childhood acute leukemia cells for CD95-induced apoptosis. Int J Cancer 2010; 126: 2216-2228

26. Loeder S, Fakler M, Schoeneberger $\mathrm{H}$, Cristofanon S, Leibacher J, Vanlangenakker $\mathrm{N}$ et al. RIP1 is required for IAP inhibitor-mediated sensitization of childhood acute leukemia cells to chemotherapy-induced apoptosis. Leukemia 2012; 26: 1020-1029.

27. Ganetsky A. The role of decitabine for the treatment of acute myeloid leukemia. Ann Pharmacother 2012; 46: 1511-1517

28. Fulda S, Meyer E, Friesen C, Susin SA, Kroemer G, Debatin KM. Cell type specific involvement of death receptor and mitochondrial pathways in drug-induced apoptosis. Oncogene 2001; 20: 1063-1075.

29. Fulda S, Debatin KM. 5-Aza-2'-deoxycytidine and IFN-gamma cooperate to sensitize for TRAIL-induced apoptosis by upregulating caspase-8. Oncogene 2006; 25: 5125-5133.

30. Petersen SL, Wang L, Yalcin-Chin A, Li L, Peyton M, Minna J et al. Autocrine TNFalpha signaling renders human cancer cells susceptible to Smac-mimetic-induced apoptosis. Cancer Cell 2007; 12: 445-456.

31. Fulda S, Galluzzi L, Kroemer G. Targeting mitochondria for cancer therapy. Nat Rev Drug Discov 2010; 9: 447-464.

32. Fulda S. Exploiting inhibitor of apoptosis proteins as therapeutic targets in hematological malignancies. Leukemia 2012; 26: 1155-1165.

33. Weisberg E, Kung AL, Wright RD, Moreno D, Catley L, Ray A et al. Potentiation of antileukemic therapies by Smac mimetic, LBW242: effects on mutant FLT3-expressing cells. Mol Cancer Ther 2007; 6: 1951-1961

34. Weisberg E, Ray A, Barrett R, Nelson E, Christie AL, Porter D et al. Smac mimetics: implications for enhancement of targeted therapies in leukemia. Leukemia 2010; 24: 2100-2109

35. Carter BZ, Gronda M, Wang Z, Welsh K, Pinilla C, Andreeff M et al. Small-molecule XIAP inhibitors derepress downstream effector caspases and induce apoptosis of acute myeloid leukemia cells. Blood 2005; 105: 4043-4050.

36. Servida F, Lecis D, Scavullo C, Drago C, Seneci P, Carlo-Stella $C$ et al. Novel second mitochondria-derived activator of caspases (Smac) mimetic compounds sensitize human leukemic cell lines to conventional chemotherapeutic drug-induced and death receptormediated apoptosis. Invest New Drugs 2011; 29: 1264-1275. 
37. Fabre C, Grosjean J, Tailler M, Boehrer S, Ades L, Perfettini JL et al. A novel effect of DNA methyltransferase and histone deacetylase inhibitors: NFkappaB inhibition in malignant myeloblasts. Cell Cycle 2008; 7: 2139-2145.

38. Valdez BC, Li Y, Murray D, Corn P, Champlin RE, Andersson BS. 5-Aza-2'-deoxycytidine sensitizes busulfan-resistant myeloid leukemia cells by regulating expression of genes involved in cell cycle checkpoint and apoptosis. Leuk Res 2010; 34: 364-372.

39. Laukens B, Jennewein C, Schenk B, Vanlangenakker N, Schier A, Cristofanon S et al. Smac mimetic bypasses apoptosis resistance in FADD- or caspase-8-deficient cells by priming for tumor necrosis factor alpha-induced necroptosis. Neoplasia 2011; 13: 971-979.

40. Vanlangenakker N, Vanden Berghe T, Bogaert P, Laukens B, Zobel K, Deshayes K et al. cIAP1 and TAK1 protect cells from TNF-induced necrosis by preventing RIP1/RIP3dependent reactive oxygen species production. Cell Death Differ 2011; 18: 656-665.

41. Horita H, Frankel AE, Thorburn A. Acute myeloid leukemia-targeted toxin activates both apoptotic and necroptotic death mechanisms. PLOS One 2008; 3: e3909.

42. Marcucci G, Silverman L, Eller M, Lintz L, Beach CL. Bioavailability of azacitidine subcutaneous versus intravenous in patients with the myelodysplastic syndromes. J Clin Pharmacol 2005; 45: 597-602.

43. Cashen AF, Shah AK, Todt L, Fisher N, DiPersio J. Pharmacokinetics of decitabine administered as a $3-\mathrm{h}$ infusion to patients with acute myeloid leukemia (AML) or myelodysplastic syndrome (MDS). Cancer Chemother Pharmacol 2008; 61: 759-766.
44. Blum W, Klisovic RB, Hackanson B, Liu Z, Liu S, Devine H et al. Phase I study of decitabine alone or in combination with valproic acid in acute myeloid leukemia. J Clin Oncol 2007; 25: 3884-3891.

45. Fulda S, Strauss G, Meyer E, Debatin KM. Functional CD95 ligand and CD95 deathinducing signaling complex in activation-induced cell death and doxorubicin-induced apoptosis in leukemic T cells. Blood 2000; 95: 301-308.

46. Tchoghandjian A, Jennewein C, Eckhardt I, Rajalingam K, Fulda S. Identification of noncanonical NF-kappaB signaling as a critical mediator of Smac mimetic-stimulated migration and invasion of glioblastoma cells. Cell Death Dis 2013; 4: e564.

47. Chou TC. The median-effect principle and the combination index for quantitation of synergism and antagonism. In: Chou TC (eds). Synergism and Antagonism in Chemotherapy. Academic Press: San Diego, USA, 1991. pp 61-102.

(i) $\odot$ Cell Death and Disease is an open-access journal published by Nature Publishing Group. This work is

licensed under a Creative Commons Attribution-NonCommercialNoDerivs 3.0 Unported License. To view a copy of this license, visit http://creativecommons.org/licenses/by-nc-nd/3.0/

\section{Supplementary Information accompanies this paper on Cell Death and Disease website (http://www.nature.com/cddis)}

